he derives between wine harvest dates and glacier movements (page 79), he hopes that "young researchers in France, Hungary or Switzerland will work out the same sort of chronology on wine quantity for their own countries as Müller has provided for Germany".

The actual change in air temperature (about $1^{\circ} \mathrm{C}$ ) between the little ice age and the recent "amelioration" in England, which seems small to the layman, makes about a month's difference to the length of the growing season. Both this and the cooling which has set in during the last two decades receive careful attention in Professor Ladurie's book, along with its pleasing production and printing.

R. F. M. HaY

H. H. LAMB

\section{Excavation Under Water}

Underwater Archeology: a Nascent Discipline. (Monuments and Museums, XIII.) Pp. 306. (Unesco: Paris, 1972.) 44 francs; $\$ 11 ; £ 3.30$.

THIs book is in some respects aptly titled: underwater archaeology is a discipline which to a large extent is (as a dictionary defines "nascent") "in the act of being born, not yet mature". But it is misleading to apply a blanket description to so wide-ranging a subject, for, as the book clearly shows, some of the results so far obtained have been markedly less immature than others. For this reason it is particularly useful to find that the wide spectrum of results summarized here have been, in the main, chronicled by their various progenitors. The work of Professor Bass and his Pennsylvania University colleagues on ancient shipwrecks in the eastern Mediterranean bears comparison with the most exacting archaeo. logical standards in or out of the water - as Bass himself stresses it should do. Likewise the well-known Wasa salvage, the excavation of wrecks from the drained polders of the Zuider Zee, the recovery of the Skuldelev viking ships from Roskilde Fjord, the Bremen Cog excavation, the work on ancient harbours and other submerged sites in the Mediterranean and elsewhere, and the fascinatingly precise sectioning of prehistoric remains in the Lake of Zurich, all weigh heavily on the credit side of the archaeological balance.

On the debit side, however, much work carried out over the past two decades on early wrecks on the eastern seaboard of the Americas seems to have been disturbingly inadequate and destructive, doubtless because privately sponsored treasure hunting appears to have been the primary motivation behind their discovery and excavation. Although structural remains of vessels dating back to the sixteenth century have been found there in some profu- sion, thus potentially covering an important and ill-documented period in the development of shipbuilding technology, Peterson's chapter gives no indication either in text or references of the existence of any published plans of such remains. To some extent the same criticism could be levelled at a good deal of what has been going on in our own waters, though the book, rather surprisingly, makes no mention of British work. It is worth reflecting that a close relationship exists between the quality of results achieved in a particular country and its government's degree of constructive involvement in this field: it is no coincidence that to date such involvement has been, both in the United States and in Britain, almost negligible.

The book includes useful chapters on techniques, not all of which, however, are wholly up to date. Williams's chapter on photogrammetric survey is practical and good, but Townsend's review of conservation procedures is less adequate, and-in common with the two other conservation chapters-does not mention important recent improve. ments in the treatment of waterlogged wood.

There is much in this book which is good, though a substantial amount is bad and more still is indifferent. This accurately mirrors the varying standards to be found within this new discipline as it endures its birth-pangs, and the book as a whole thus provides a useful survey of how the subject stands at present and where its strengths and weaknesses lie. As its editors themselves point out, it is a status report and not a textbook.

\section{Colin J. M. Martin}

\section{Applied Relativity}

Gravitation and Cosmology: Principles and Applications of the General Theory of Relativity. By Steven Weinberg. Pp. xxviii +657 . (John Wiley: New York and London, September 1972.) $£ 8$.

IN the last twenty years general relativity has developed dramatically in two opposite directions. On the one hand more powerful mathematical methods have clarified the general structure and significance of the theory, while on the other it has come into close contact with modern astrophysics. Put crudely, but not altogether inaccurately, we now have two subjects: topological relativity and engineering relativity. This book is unashamedly about engineering relativity. It is written by a man well known for his brilliant contributions to the theory of elementary particles, and for his occasional forays into relativistic astrophysics. In my opinion the book is quite superb as an introduction to its subject.
It begins with a brief, physically oriented, account of special and general relativity in sufficient mathematical detail for the later astrophysical applications. These applications begin with a treatment of stellar equilibrium and collapse. The level of this treatment is that of an introductory survey rather than a comprehensive account of the kind that can be found in Zeldovich and Novikov's book Relativistic Astrophysics or in various summer school lecture notes by Thorne. Nevertheless I would recommend it as an excellent introduction to the more detailed treatments. The book then reverts to a consideration of some mathematical developments used in general relativity, namely, concerning the action principle, the tetrad formalism and space-times which possess symmetries. It is not clear to me why this material is inserted into the middle of the astrophysical part of the book, rather than in the chapters on general relativity. It is true that the discussion of symmetries is of basic importance for the following section on cosmology, but it is also needed for the derivation of the Schwarzschild solution, where indeed a forward reference has to be made.

Finally we come to the cosmology section, which occupies the last two hundred or so pages of the book. The treatment here is up to date and has a physical orientation which I found very satisfying. Of particular value are the sections on intergalactic emission and absorption processes, the cosmic microwave radiation background, the thermal history of the early universe, and the formation of galaxies. In the final chapter there is a brief account of non-standard models of the universe which includes relativistic models with a cosmical constant, the steady state theory, and models with a varying constant of gravitation.

The book as a whole is clearly written, is pervaded by physical insight, and contains sufficient mathematical development to serve as an introduction to more detailed treatments and to the original literature. I recommend it to all physicists who want to gain a serious understanding of modern relativistic astrophysics, to students who wish to start work in this subject, and even to my colleagues.

I have left myself enough space to air one small quarrel which I have with the author. It concerns his attitude to the principle of equivalence and to Mach's principle. In the preface he states that the reason why gravitation obeys the equivalence principle is not to be found in classical physics but in the constraints imposed by the quantum theory of gravitation. In the body of the book he states that there is a sense in which the equivalence principle and Mach's principle are in direct opposi- 